\title{
Nano-colloids of $\mathrm{Sn}_{2} \mathrm{P}_{2} \mathrm{~S}_{6}$ in Nematic Liquid Crystal Pentyl-cianobiphenile
}

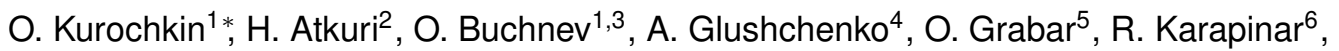

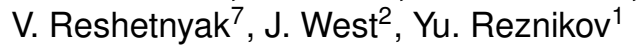 \\ 1 Institute of Physics, National Academy of Sciences of Ukraine, 46 Nauky avenue, Kyiv 03028, Ukraine \\ 2 Liquid Crystal Institute, Kent State University, Kent, Ohio, 44242, USA \\ 3 University of Southampton, Highfield, Southampton, SO17 1BJ, United Kingdom \\ 4 University of Colorado at Colorado Springs, Department of Physics, Colorado Springs, CO 80918, USA \\ 5 Institute of Solid State Physics and Chemistry, Uzhgorod State University, 46 Pidhirna Str., Uzhgorod \\ 294000, Ukraine \\ ${ }^{6}$ Faculty of Arts and Sciences Department of Physics, Yuzuncu Yil University, Van, 65080, Turkey \\ 7 National Taras Shevchenko University of Kyiv, Physics Faculty, Volodymyrs'ka Str. 64, Kyiv, 01601, Ukraine
}

Received December 18, 2009, in final form June 9, 2010

It has been shown experimentally that the ferroelectric nano-particles, in common with other molecular additives, shift the clearing temperature, $T_{\mathrm{c}}$, extending or reducing the two-phase coexistent region and changing the average order parameter of the single-component nematics. An increase of up to $11^{\circ} \mathrm{C}$ or a smaller decrease of as much as $3^{\circ} \mathrm{C}$ of $T_{\mathrm{c}}$, and corresponding changes of the order parameter were observed. In all cases the order parameter of the colloid followed the universal temperature behaviour, which is a characteristic of LCs with molecular additives.

Key words: liquid crystals, ferroelectric nanoparticles

PACS: 77.84.Nh, 42.70.Df, 78.15.+e, 47.57.J-, 77.84.Lf, 78.67.SC

\section{Introduction}

Different types of nano-particles (dielectric [1, 2], ferroelectric [3], ferromagnetic [4] and metal [5]) have been dispersed in liquid crystals (LCs) to form unique anisotropic colloids. Nano-particles can significantly change the basic physical properties of LC matrix by "sharing" their intrinsic properties with the LC host. Previous research has shown that doping a nematic host with ferromagnetic nano-particles introduces ferromagnetic properties into the diamagnetic matrix. This doping also makes the resulting colloid super-sensitive to a magnetic field [4]. Colloids of ferroelectric nanoparticles dispersed in a nematic host introduce ferroelectricity; they become sensitive to the sign of an electric field [3].

Recently the unique properties of dilute colloids of ferroelectric nano-particles in LCs were reported [3, 6 9, 37]. These colloids are stable because the particles do not agglomerate at low concentrations (less than $0.1-1 \%$ by weight). The important point is that the single nano-particles are so small that the anchoring parameter $\xi=W R / K \ll 1$ ( $W$ is the anchoring energy, $K$ is the elastic constant, $R$ is the characteristic size of the particles). For this condition the nanoparticles do not substantially disturb the orientation of the LC director producing a macroscopically uniform alignment. As a result, the ferroelectric colloid appears similar to a pure LC with no readily apparent evidence of dissolved particles. At the same time the nano-particles may produce substantial changes in the physical properties of the liquid crystal host - they enhance the order parameter, birefringence and dielectric anisotropy of nematics $[3,6]$, improving the alignment order of a surface-stabilized ferroelectric LCs [9].

*E-mail: kurochkin@iop.kiev.ua 
We have previously considered the change of the average order parameter of the LC, $\bar{S}$, due to the strong electric field around the ferroelectric nano-particles to be the primary factor affecting the macroscopic properties of nematics [3, 6]. In this sense, the behaviour of the nano-particles in a LC is reminiscent of the behaviour of low-molecular weight molecular dopants in nematics. Chen and Luchkhrust as far back in 1969 concluded that the temperature dependence of $\bar{S}(\tau), \tau=T /\left(T_{\mathrm{c}}+\right.$ $273)$, for a nematic LC with additives is the universal function of the reduced temperature [12]. It was also shown that the function $\bar{S}(\tau)$ did not depend on the chemical structure of the additives and coincided with the dependence $\bar{S}_{0}(\tau)$ for the pure LC matrix. Later, Pinkevich et al. [13] showed that this universality follows from the standard Grandjean-Maier-Saupe (GMS) molecular field theory. The sign of the shift of $\tau$ and $T_{\mathrm{c}}$ is determined by the relationship between the amplitude of inter-molecular interaction of LC molecules, $G_{\mathrm{lc}-\mathrm{lc}}$, and the amplitude of interaction "LC molecule - additive molecule", $G_{\mathrm{lc}-\mathrm{imp}}$. In the case of non-mesogenic additives, $G_{\mathrm{lc}-\mathrm{lc}}>G_{\mathrm{lc}-\mathrm{imp}}$, the local order parameter around the additive is smaller than in a pure LC, and the shift of the clearing temperature, $\Delta T_{\mathrm{c}}<0$. Mesogenic dopants can interact with liquid crystal molecules more strongly than liquid crystal molecules with themselves $G_{\mathrm{lc}-\mathrm{lc}}<G_{\mathrm{lc}-\mathrm{imp}}$. Therefore, mesogenic additives can increase the local ordering and increase the clearing temperature, demonstrating that $\Delta T_{\mathrm{c}}>0$.

The goal of the present work is to follow the analogy between the effects of the ferroelectric nano-particles and low-molecular weight dopants on the properties of nematic LCs. It was found experimentally that the nano-particles, by analogy with molecular additives, show the universal temperature behaviour of the average order parameter. The experimental results are confirmed within the framework of GMS molecular field formalism in which the colloid is considered as a LC host with undisturbed order parameter, $S_{\mathrm{LC}}$, with clusters of LC molecules, having order parameter, $S_{\mathrm{cl}}$, which differs from $S_{\mathrm{LC}}$ due to the nano-particles.

\section{Materials}

To our knowledge, three types of ferroelectric materials have been studied as dopants of nanoparticles in LC matrixes: $\mathrm{Sn}_{2} \mathrm{P}_{2} \mathrm{~S}_{6}[3,7,6,8,14-16], \mathrm{BaTiO}_{3}[6,7$, , 17] and $\mathrm{ZnO}$ [9]. Since the majority of the experimental data were collected for the material $\mathrm{Sn}_{2} \mathrm{P}_{2} \mathrm{~S}_{6}$ (tin thiohypodiphosphate) and the nano-colloids based on this are extremely promising for photorefractive applications [14, 15, 18], this ferroelectric material was chosen for our experiments. At room temperature macroscopic $\mathrm{Sn}_{2} \mathrm{P}_{2} \mathrm{~S}_{6}$ crystals have a spontaneous polarization of $14 \mu \mathrm{C} \mathrm{cm}^{-2}$ parallel to the [100] direction in the monoclinic unit cell chosen according to [19]. The Curie temperature of $\mathrm{Sn}_{2} \mathrm{P}_{2} \mathrm{~S}_{6}$ in a macroscopic crystal is $T_{\text {Curie }} \approx 64^{\circ} \mathrm{C}\left[20,21\right.$. The value of the dielectric constants of $\mathrm{Sn}_{2} \mathrm{P}_{2} \mathrm{~S}_{6}$ strongly depends on the quality of the samples [22]. Typically, the low-frequency dielectric constant measured along the polar axis at room temperature is $\varepsilon_{\|} \approx 300$ in a single domain crystal, and is about two times larger in a polydomain state, due to a domain wall contribution to the dielectric permittivity. On approaching $T_{\mathrm{c}}$ the dielectric constant follows the Curie-Weiss law, and near $T_{\text {Curie }}$ reaches the peak value of the order of 104-105 [23].

Crystals of $\mathrm{Sn}_{2} \mathrm{P}_{2} \mathrm{~S}_{6}$ were ground together with oleic acid as a surfactant in a weight ratio 4:1 in a Fritsch 00-502 vibration micro-mill. The particles had been milling for 8-10 hours per day, $130 \mathrm{~h}$ in total. The resulting dispersion was characterized by an NT-MDT atomic force microscope. This was accomplished by dispersing the ferroelectric particles in methanol in a weight ratio 1:3000. A drop of the dispersion was deposited on a microscope glass slide and an AFM scan was obtained after evaporation of the methanol. It was found that the particles had quasi-spherical shape with the average size, $d \approx 20 \mathrm{~nm}$ and the size dispersion $\delta d \approx 10 \mathrm{~nm}$. At this size the ferroelectric particles have a single domain structure [24, 25]. Some of the particles were combined in the agglomerates containing 3-5 particles. The milling did not destroy the ferroelectric phase of the $\mathrm{Sn}_{2} \mathrm{P}_{2} \mathrm{~S}_{6}$. We observed a peak of the ferroelectric-paraelectric transition at $T_{\text {Curie }} \approx 64^{\circ} \mathrm{C}$ using differential scanning calorimetry technique (Perkin-Elmer). This corresponds well with the phase transition point of the bulk $\mathrm{Sn}_{2} \mathrm{P}_{2} \mathrm{~S}_{6}$ crystals.

In the majority of previous studies the multi-component nematic LC-mixtures were utilized as a host medium for the colloid preparation. In this case the physical interpretation of the results is 
seriously complicated by the many factors affecting the properties of the multi-component LC nanoparticle dispersions. For instance, different components of the LC-mixture may be preferentially adsorbed on the nano-particle surface. This will result in the enrichment of one component at the particle surface and its depletion in the "bulk" of the host, and will clearly affect the measured macroscopic properties of the dispersion. Also, some molecular components of LC mixtures have permanent electric dipoles different for each component. This will result in the spatial separation of the molecular components on a nanometer scale due to the strong electric field gradient produced near the ferroelectric nano-particles. Another serious problem that appears during preparation of the colloids in a multi-component mixture is a possible change of molecular composition during the preparation procedure. As a consequence, the properties of the final matrix may differ from the initial one [26]. The difference in the properties due to the change of the composition may be comparable with the changes associated with the presence of the particles and may mask the real action of the nanoparticles.

To avoid the complications associated with a multi-component host, we used a single-component nematic, pentyl-cianobephenyle $(5 \mathrm{CB})$ from EMI (clearing temperature, $T_{\mathrm{c}}=34.5^{\circ} \mathrm{C}$ ) as the host medium for the colloid. We can therefore assume that any observed changes are caused by interactions of the particles with the surrounding host rather than by any change in the composition and spatial separation of the components of the matrix.

The mixture of the nano-particles with the surfactant was dispersed in heptane at the weight concentration $7 \%$. After precipitation of the big agglomerates at the bottom of the vessel, the top $2 / 3$ of the mixture volume was decanted, stirred ultrasonically for $30 \mathrm{~s}$ and added to $5 \mathrm{CB}$ in a weight ratio $1: 2$. This mixture was stirred ultrasonically again and put onto a hot-stage at $T=45^{\circ} \mathrm{C}$ for solvent evaporation. The full evaporation of the heptane was confirmed by IR spectroscopy measurements. The resulting nematic colloid had a volume fraction of particles $C_{\mathrm{v}} \approx 0.3$ vol. $\%$. We prepared several colloids with the described procedure using $\mathrm{Sn}_{2} \mathrm{P}_{2} \mathrm{~S}_{6}$ crystals from the same batch, as well as from different batches.

The colloids were studied in cells comprised of two ITO coated glass substrates. The substrates were covered with rubbed polyamide polymer layers to produce uniform homogenous alignment. The substrates were separated with rod-like polymer spacers to produce a cell gap in the range of $d \approx 20 \mu \mathrm{m}$. The cells were capillary filled at elevated temperature, $T>T_{\mathrm{c}}$. Observations of all samples in a polarizing microscope showed the same uniform planar structures in the cells filled with the pure nematic and with the colloid.

\section{Results}

The ferroelectric nano-particles act as molecular dopants if (a) they do not disturb the director; and $(b)$ the particles change the clearing temperature, extend the two-phase region of "nematicisotropic phase" transition and change the order parameter in a way that the dependence $\bar{S}_{\text {col }}(\tau)$ is a universal function of the reduced temperature $\tau$ that coincides with the dependence $\bar{S}_{\mathrm{LC}}(\tau)$ for pure LC [12, 27, 28, 37].

The validity of the conditions listed above was checked by the following experiments.

(a). The detailed observation of the samples in a polarization microscope did not show any additional distortions of the director in the colloid compared with the pure LC. This corresponds to our measurements of the size of the particles, $d \approx 20 \mathrm{~nm}$ at which the anchoring parameter $\xi \ll 1$ and no director orientational defects should be formed. The colloids in the cells were stable for at least several months and we did not find, with time, any visible aggregations of the particles or formation of defects by optical microscope observations. Therefore, condition (a) is valid.

We suggest that besides the surfactant coating, the high stability of the colloid is caused by the orientational elasticity of mesophase. If the particles agglomerate, their effective size increases and at some point requires the creation of a high energy defect. This will prevent agglomeration and maintain the dispersion as single particles, or agglomerations with dimensions below the threshold requiring the formation of a defect.

(b). In order to check the condition (b), the clearing temperature, $T_{\mathrm{c}}$, of the pure $5 \mathrm{CB}$ and 
Table 1. Samples of different ferroelectric colloids on the basis of $5 \mathrm{CB}$.

\begin{tabular}{|c|c|c|c|}
\hline $\begin{array}{l}\text { Sample } \\
\text { Number }\end{array}$ & Shift $\Delta T_{\mathrm{c}},{ }^{\circ} \mathbf{C}$ & $\begin{array}{l}\text { Width of } \\
\text { two-phase } \\
\text { region, } \Delta T_{\mathrm{NI}} \text {, } \\
{ }^{\circ} \mathbf{C}\end{array}$ & Comment \\
\hline 1 & +3.0 & 0.5 & $\mathrm{Sn}_{2} \mathrm{P}_{2} \mathrm{~S}_{6}$ from batch \#1 \\
\hline 2 & +11.1 & 1.6 & $\mathrm{Sn}_{2} \mathrm{P}_{2} \mathrm{~S}_{6}$ from batch \#2 \\
\hline 3 & +3.3 & 0.9 & $\mathrm{Sn}_{2} \mathrm{P}_{2} \mathrm{~S}_{6}$ from batch $\# 3$ \\
\hline 4 & +1.5 & $\mathrm{n} / \mathrm{a}$ & $\begin{array}{l}\mathrm{Sn}_{2} \mathrm{P}_{2} \mathrm{~S}_{6} \text { from batch } \# 3 . \\
\text { Sample prepared in a week after the } \\
\text { sample } \# 3\end{array}$ \\
\hline 5 & -0.4 & 0.2 & $\begin{array}{l}\mathrm{Sn}_{2} \mathrm{P}_{2} \mathrm{~S}_{6} \text { from batch } \# 3 . \\
\text { Sample prepared in two weeks after the } \\
\text { sample \#3 }\end{array}$ \\
\hline 6 & +3.2 & $\mathrm{n} / \mathrm{a}$ & $\mathrm{Sn}_{2} \mathrm{P}_{2} \mathrm{~S}_{6}$ from batch \#4 \\
\hline 7 & -1.9 & $\mathrm{n} / \mathrm{a}$ & $\mathrm{Sn}_{2} \mathrm{P}_{2} \mathrm{~S}_{6}$ from batch $\# 5$ \\
\hline 8 & -2.8 & 0.3 & $\mathrm{Sn}_{2} \mathrm{P}_{2} \mathrm{~S}_{6}$ from batch \#6 \\
\hline
\end{tabular}

colloids was measured by observing the LC textures in a polarizing microscope at slow temperature change $\left(\sim 0.1^{\circ} \mathrm{C} \mathrm{min}^{-1}\right)$ in a hot-stage. Most previous experiments showed that the addition of the $\mathrm{Sn}_{2} \mathrm{P}_{2} \mathrm{~S}_{6}$ nano-particles leads to an increase in the clearing temperature of the multi-component LC [3, 7, 13 15], but a decrease of $T_{\mathrm{c}}$ in some experiments was also observed [8, 9]. In order to identify whether the sign of $T_{\mathrm{c}}$, and accordingly, $\bar{S}_{\text {col }}$ is caused by changes in the composition of the multi-component mixtures [3, 7, 9, 13-15], or exists also in a single component LC, we have measured the values of $T_{\mathrm{c}}$ in seven samples of $\mathrm{Sn}_{2} \mathrm{P}_{2} \mathrm{~S}_{6}$ particles dispersed in $5 \mathrm{CB}$ and compared them with $T_{\mathrm{c}}$ of the pure $5 \mathrm{CB}$. Despite identical fabrication procedure, in some cells we observed an increase of the average order parameter and clearing temperature of the LC while in others we observed a decrease (table 11). The difference in the results obtained for the different batches of the $\mathrm{Sn}_{2} \mathrm{P}_{2} \mathrm{~S}_{6}$ may be explained by uncontrolled stehiometry of the initial crystals which can arise during their growth. Concerning the samples 3, 4 and 5, which were produced from the same batch of $\mathrm{Sn}_{2} \mathrm{P}_{2} \mathrm{~S}_{6}$, the only difference is the time between the preparation of the milled nano-particles and fabrication of the sample (dispersion of the particles in heptanes, adding of $5 \mathrm{CB}$ and evaporation of heptanes).

Expansion of the two phase region, $\Delta T_{\mathrm{NI}}$, (the co-existence of the nematic and isotropic phases region), in comparison with the pure $\mathrm{LC}\left(\Delta T_{\mathrm{NI}} \leqslant 0.1^{\circ} \mathrm{C}\right)$ was also observed (table 1). The increase of the width of the two-phase region, $\Delta T_{\mathrm{NI}}$ corresponds to the increase of the clearing point, $\Delta T_{\mathrm{c}}$ This corresponds to the effect [29] on the phase transition in a LC with non-mesogenic molecular additives.

The measured values $\Delta T_{\mathrm{NI}}$ and $T_{\mathrm{c}}$ remained constant for at least 10 months. Moreover, a repeated heating of the cells well into the isotropic phase, in the presence of a high electric field did not affect the values of $\Delta T_{\mathrm{NI}}$ and $T_{\mathrm{c}}$. For example, sample \#3 was heated above $T_{\mathrm{c}}$ seven times

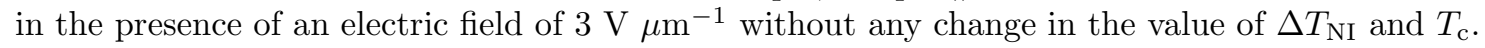

The average order parameter of the colloid, $\bar{S}_{\mathrm{col}}$, and the pure LC, $\bar{S}_{5 \mathrm{CB}}$, as a function of temperature was measured using the guest-dye technique [30]. Methyl Red (MR) was used as the guest dye. In the guest-dye technique the order parameter is determined from the optical density of the probe dye molecules absorption measured for light polarization parallel $\left(A_{\|}\right)$and perpendicular 
$\left(A_{\perp}\right)$ to the LC director orientation:

$$
\bar{S}=\frac{A_{\|}-A_{\perp}}{A_{\|}+2 A_{\perp}} .
$$

Strictly speaking, this method does not yield the value of the average order parameter of a LC, $\bar{S}_{5 \mathrm{CB}}$, but the average order parameter of dye molecules orientation, $\bar{S}_{\text {dye }}$. However, the comparison

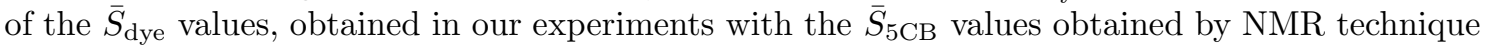
in [31] shows the difference of only $3 \%$. Therefore, it is reasonable to consider that $\bar{S}_{5 \mathrm{CB}} \approx \bar{S}_{\text {dye. The }}$ dye is even more reliable at monitoring changes in the order parameter as compared to measuring the absolute value of the order parameter.

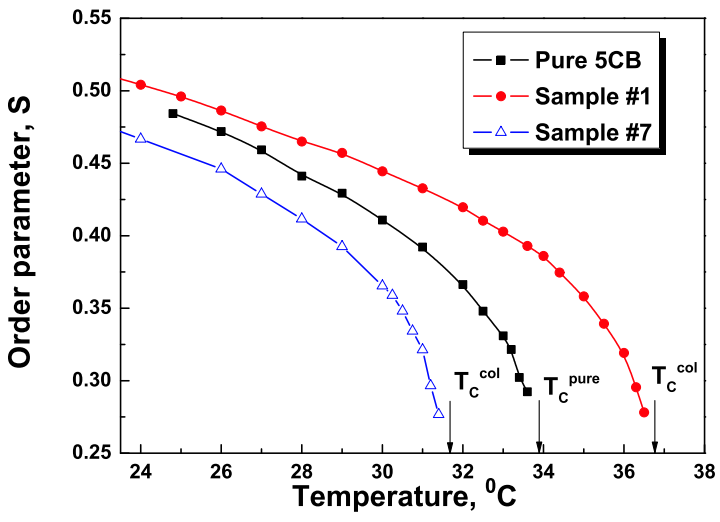

(a)

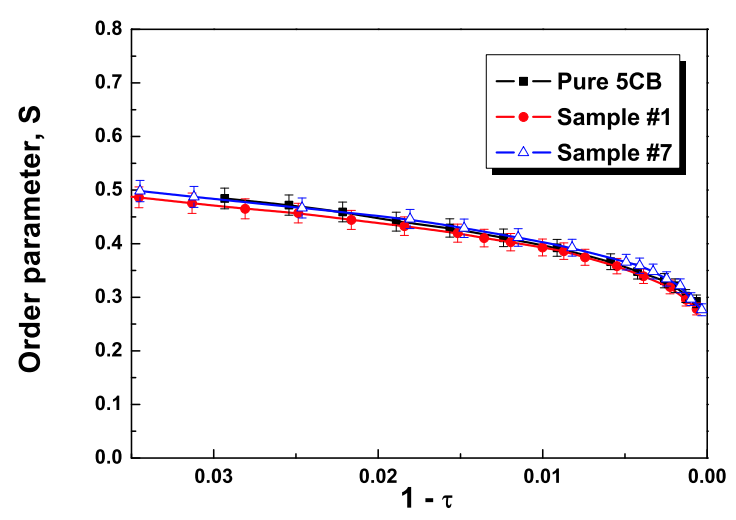

(b)

Figure 1. Dependences of the order parameters of the pure 5CB and the colloids (samples \#1;7) on the temperature (a) and the reduced temperature (b).

In order to obtain the temperature dependencies of the order parameter of pure 5CB and the colloid, we chose the samples \#1;7 that showed similar absolute values but opposite signs of $\Delta T_{\mathrm{c}}$ (table 1). The results of the measurements $\bar{S}_{5 \mathrm{CB}}(T)$ and $\bar{S}_{\mathrm{col}}(T)$ are presented in figure 11a. In sample \#1 $\left(\Delta T_{\mathrm{c}}=3.0^{\circ} \mathrm{C}\right)$ an increase of the average order parameter was observed, however a decrease of order parameter was observed in sample $\# 7\left(\Delta T_{\mathrm{c}}=-1.9^{\circ} \mathrm{C}\right)$ compared to pure $5 \mathrm{CB}$. The important point is that despite the value and even the sign of the changes of $S$ and $T_{\mathrm{c}}$ varying from sample to sample, in all cases the curves in the temperature dependences of $\bar{S}_{5 \mathrm{CB}}(\tau)$ and $\bar{S}_{\mathrm{col}}(\tau)$ plotted against the reduced temperature $\tau=(T+273) /\left(T_{\mathrm{c}}+273\right)$ perfectly coincided (figure 19) as is seen for LC doped with molecular additives.

Thus, the doping of $5 \mathrm{CB}$ with $\mathrm{Sn}_{2} \mathrm{P}_{2} \mathrm{~S}_{6}$ particles changes the clearing temperature and the order parameter in a way that the temperature dependence $\bar{S}_{\text {col }}(\tau)$ coincides with the dependence $\bar{S}_{\mathrm{LC}}(\tau)$ for pure LC, and the presence of the particles expands the two-phase region of "nematic-isotropic phase" transition, i. e. the condition (b) is valid.

The results described above show that the particles change the average order parameter of the LC matrix. Since the order parameter strongly affects the key parameters of LCs, such as dielectric anisotropy, birefringence, Frank constants, etc., it makes possible the control of LC properties by a non-chemical method. From this point of view it is very important to know if the properties of the particles, such as the optical polarizabilities and the low frequency dielectric constants, effect the values $n_{\mathrm{a}}$ and $\varepsilon_{\mathrm{a}}$ of the colloid. To do this, we measured the temperature dependences of $\varepsilon_{\mathrm{a}}(T)$ and $n_{\mathrm{a}}(T)$ in the pure 5CB and in the colloid. The temperature dependences $n_{\mathrm{a}}(T)$ were determined using a retardation technique that allows the measurement of the phase shift between e- and owaves $\varphi=\pi d n_{\mathrm{a}} / \lambda$ in planar cells $(d=50 \mu \mathrm{m})$. An impedance analyzer was used to measure the dielectric constants of the colloid and the pure LC in the cells with homeotropic and planar LC orientation. The cells were $20 \mu \mathrm{m}$ thick and contained guard electrodes. The dielectric constants parallel to the director, $\varepsilon_{\|}$, and perpendicular to the director, $\varepsilon_{\perp}$, were determined measuring the capacitance of the cells with homeotropic and planar LC orientation respectively. 
The birefringence and dielectric constants of the sample \#2 was measured. Changes in the birefringence in the colloid explained by the change of the order parameter of the matrix, and the direct contribution of the material particles to the value of $n_{\mathrm{a}}^{\text {col }}$ is negligible. This is not surprising taking into account that the birefringence of the $\mathrm{Sn}_{2} \mathrm{P}_{2} \mathrm{~S}_{6}$ single crystals, $n_{\mathrm{a}}^{\text {part }} \approx 0.15$ is close to the birefringence of the $5 \mathrm{CB}\left(n_{\mathrm{a}}^{\mathrm{NLC}} \approx 0.17\right)$ and the concentration of particles is small $\left(C_{\mathrm{v}} \approx 0.3 \mathrm{vol} . \%\right)$. Alternatively, the spontaneous polarization of the $\mathrm{Sn}_{2} \mathrm{P}_{2} \mathrm{~S}_{6}$ single crystals is very high $\left(P \approx 14 \mu \mathrm{C} \mathrm{cm}^{-2}\right)$ and the dielectric constant of $\mathrm{Sn}_{2} \mathrm{P}_{2} \mathrm{~S}_{6}, \varepsilon \sim 10^{2}-10^{3}$ is much higher than the dielectric constant of $5 \mathrm{CB}$. Therefore, one may expect that the dielectric constant of the particles can notably contribute to the effective dielectric constant of the colloid [32]. Indeed, a strong enhancement of the dielectric anisotropy that increases near the phase transition was observed. At the same time we found a small discrepancy between the dependence of $\varepsilon_{\mathrm{LC}}(\tau)$ and $\varepsilon_{\mathrm{col}}(\tau)$, but it was difficult to conclude whether it was an objective result or a systematic experimental error (the measurements of $\varepsilon_{\|}$and a decrease of $\varepsilon_{\perp}$ were carried out in different cells). Therefore, we assume that the nano-particles have a small, if any, contribution to the effective dielectric constants of the colloid.

We also compared the Freedericksz transition voltage in a symmetric planar cell filled with the pure $5 \mathrm{CB}$ to one filled with the colloid (sample \#2). The transition voltage for pure a LC is determined by the formula [30]

$$
U=\pi \sqrt{\frac{4 \pi K_{11}}{\varepsilon_{\mathrm{a}}}}
$$

and for the colloid of ferroelectric nano-particles the same formula applies, except that $\varepsilon_{a}$ is now the anisotropy of the effective dielectric constant, $\varepsilon_{\mathrm{a}, \text { eff }}$, that depends on the concentration and polarization of the ferroelectric particles [33].

The dielectric anisotropy of a LC is proportional to the order parameter, $\varepsilon_{\mathrm{a}} \sim S$, while the elastic constant is proportional to the square of the of the order parameter, $K_{11} \sim S^{2}$ [34]. Assuming the same dependencies on $S$ in the colloid and applying the experimental data for $\varepsilon_{\mathrm{a}, \mathrm{LC}} / \varepsilon_{\mathrm{a}, \text { part }}=$ $S_{\mathrm{LC}} / S_{\text {part }}=0.86$ and $K_{11, \mathrm{LC}} / K_{11, \text { part }}=S_{\mathrm{LC}}^{2} / S_{\text {part }}^{2}=0.79$ at room temperature, a very weak increase in Freedericksz transition voltage for the colloid, $U_{\text {col }} \approx 1.04 U_{\mathrm{LC}}$, is expected. Experimental results confirmed this estimation; we found that $U_{\mathrm{LC}}=1.84 \pm 0.02 \mathrm{~V}$ and $U_{\text {col }}=1.87 \pm 0.02 \mathrm{~V}$.

\section{Discussion}

All the experimental data described unambiguously indicate that the ferroelectric nano-particles in single-component LC behave as molecular dopants, and the change of the order parameter of the $\mathrm{LC}$ is the dominant mechanism that determines the difference between the properties of the colloid and the pure single component LC.

Considering the nature of the order parameter changes in the colloid, there are two basic mechanisms by which the ferroelectric nano-particles can change the order parameter. The first mechanism is a change of the order parameter near a boundary surface due to a difference between the "LC-anchoring surface" interaction and a molecular interaction in the bulk LC [35]. As an example, one can refer to the recent paper of Cordoyiannis et al., which observed a decrease of up to $4.9^{\circ} \mathrm{C}$ in the $I-N$ transition when the liquid crystal octylcyanobiphenyl was doped by ferromagnetic nano-particles with an organic coating [36]. In our opinion, this mechanism cannot be responsible for the observed increase of the average order parameter and the clearing temperature. Indeed, interaction of the ferroelectric nano-particles coating (oleic acid) with 5CB molecules is smaller than the intermolecular interaction in $5 \mathrm{CB}$ (doping of $5 \mathrm{CB}$ with oleic acid decreases $T_{\mathrm{c}}$ ). Therefore, this coating can only decrease the order parameter near the particles. The second basic mechanism deals with the electric field produced by the ferroelectric nano-particles. This mechanism can result in an increase of $T_{\mathrm{c}}$ and $S$ due to enhancement of the orientation coupling in a LC matrix, either due to dipole-dipole interaction between the nanoparticles and surrounding molecules, or due to an increase of the intermolecular interaction in a dipole field from the nano-particles [6]. In the last case the increase of the clearing point, $\Delta T_{\mathrm{c}}$ is related to a permanent polarization of the particles 
by the formula [6]:

$$
P=\sqrt{\frac{27 \varepsilon_{0}}{z N_{\text {part }} \gamma_{\mathrm{a}}^{2}}\left(\frac{L}{R}\right)^{3} 4.54 k_{\mathrm{B}} \Delta T_{\mathrm{c}}},
$$

where $z$ is a number of nearest neighbor molecules, $R$ is the radius of the particles, $L$ is the intermolecular distance, $N_{\text {part }}$ is the concentration of the particles, $\gamma_{\mathrm{a}}$ is the anisotropy of the polarizability of LC molecules. For our experimental conditions $z \approx 6, R \approx 35 \mathrm{~nm}, L \approx 0.5 \mathrm{~nm}$, $N_{\text {part }} \approx 2.8 \cdot 10^{19} \mathrm{~m}^{-3}, \beta_{a} \approx 1$ and $P \approx 0.04 \mathrm{C} \mathrm{m}^{-2}$, the largest observed value of $\Delta T_{\mathrm{c}}$ was $11^{\circ} \mathrm{C} 11$. The calculated value of $P$ is 3.5 times less than the reported value $P=0.14 \mathrm{C} \mathrm{m}^{-2}$ for macroscopic $\mathrm{Sn}_{2} \mathrm{P}_{2} \mathrm{~S}_{6}$ crystals. The reduced value $P$ as compared with the polarization of macroscopic crystals is reasonable because the permanent intrinsic polarization of the particles may be partially screened by charged ions that are always present in a LC. Thus, the mechanism dealing with the electric field produced by the ferroelectric particles explains the observed increase of $S$ and $T_{\mathrm{c}}$. The question of why in some experiments $S$ and $T_{\mathrm{c}}$ decreases, requires additional studies. For the time being we suggest that the permanent polarization of ferroelectric particles, which is definitely preserved after the milling of the $\mathrm{Sn}_{2} \mathrm{P}_{2} \mathrm{~S}_{6}$ crystals (see the part "Materials" of the paper) is screened by external charges in the experiments where the decrease of $S$ and $T_{\mathrm{c}}$ was observed. This suggestion is supported by the fact that the initial shift $\Delta T_{\mathrm{c}} \approx 3^{\circ} \mathrm{C}$ decreased to $\Delta T_{\mathrm{c}} \approx 1.5^{\circ} \mathrm{C}$ for the cell assembled one week after the milling of the particles and changed the sign, $\Delta T_{\mathrm{c}} \approx-0.4^{\circ} \mathrm{C}$ for the cell assembled after two weeks (table 1). We speculate that in the case of the negative $T_{\mathrm{c}}$ shift the main factor affecting the values of $S$ and $T_{\mathrm{c}}$ is either the oleic acid coating or free oleic acid molecules that are always present in the LC bulk [10]. Our preliminary measurements of IR spectra of the colloids confirmed the presence of free oleic acid molecules in the bulk LC and the oleic acid molecules bounded to the surfaces of the particles. We also found that 0.5 weight percent of oleic acid dissolved in $5 \mathrm{CB}$, decreases the clearing temperature by $\Delta T_{\mathrm{c}} \approx-1.6^{\circ} \mathrm{C}$. This value is comparable with the characteristic value of the negative shift of $T_{\mathrm{c}}$ in the colloid. It suggests that this factor alone may explain the negative component of the clearing temperature shift.

\section{Summary}

We have experimentally found that ferroelectric nano-particles, in common with other molecular additives, shift the clearing temperature, $T_{\mathrm{c}}$, extending the two-phase coexistent region and changing the average order parameter of the single-component nematics. An increase of up to $11^{\circ} \mathrm{C}$ or a smaller decrease of as much as $3^{\circ} \mathrm{C}$ of $T_{\mathrm{c}}$, and corresponding changes of the order parameter were observed. For both of these cases the order parameter of the colloid showed the universal temperature behavior, which is a characteristic of the LCs with molecular additives. We suggest that the increase of the order parameter and clearing temperature are caused by a strong electric field produced by ferroelectric particles that can be screened by outside charges in the case of the decrease of $T_{\mathrm{c}}$. The measurements of the dielectric anisotropy and the birefringence showed that their enhancement in the colloid is determined by the increase of the order parameter of the LC matrix, and the direct contribution of the particles to the values of the dielectric anisotropy and the birefringence is small.

\section{Acknowledgement}

The authors are very grateful to Christophe Blank, Lena Lopatina, Maurizo Nobili, Tim Sluckin and Jonathan Selinger for useful discussions and advice. The research described in this paper was partially supported by the grants "Composite liquid crystal and polymer materials for information technologies" and "Self-organization and structuring, physical properties of anisotropic system based on liquid crystals matrix" of the National Academy of Sciences of Ukraine, by the NATO Collaborative Linkage Grant "Colloids of ferroelectric nano-particles in nematic and cholesteric

\footnotetext{
${ }^{1}$ The estimations according to model of ferroelectric nanoparticles in nematic LCs described in the recent paper of Lopatina and Selinger [1] give a close value of $P$.
} 
liquid crystals", a grant ECO-NET 2008 no. 18843TM, the Royal Society joint project "Nanoengineering of liquid crystals for strong photorefraction response", a joint grant of the Scientific, and Technical Research Council of Turkey and the National Academy of Sciences of Ukraine "Investigation of Electro-optical Properties of Nano-particles in Liquid Crystals", and Research Corporation Cottrell College Science Award no. CC6945.

\section{References}

1. Eidenschink R., Jeu W.H., Electronics Letters, 1991, 27, 1195.

2. Guba G., et al., Mol. Cryst. Liq. Cryst., 1994, 251, 303.

3. Reznikov Yu., et al., Appl. Phys. Lett., 2003, 82, 1917.

4. Chen S-H., Amer N.M., Phys. Rev. Lett., 1983, 51, 2298.

5. Shiraishi Y., et al., Appl. Phys. Lett., 2002, 81, 2845.

6. Li F., et al., Phys. Rev. Lett., 2006, 97, 147801.

7. Copic M., Mertelj A., Buchnev O., Reznikov Yu. Phys. Rev. E., 2007, 76, 011702.

8. Ouskova E., et al., Liquid Crystals, 2003, 30, 1235.

9. Huang J.-Y., Li L.-S., Chen M.-C. J. Phys. Chem. C, 2008, 112, 5410.

10. Atkuri H., et al., J. Opt. A: Pure Appl. Opt, 2009, 11, 024006.

11. Lopatina L., Selinger J., Phys. Rev. Lett., 2009, 102, 197802.

12. Chen D., Luchkhrust G., Trans. Faraday. Soc., 1969, 65, 656.

13. Pinkevich I.P., Reznikov Yu.A., Reshetnyak V.Yu., Yaroshchuk O.V., Intern. J. Nonlinear. Opt. Phys., 1992, 1, 447.

14. Buchnev O., et al., J. Opt. Soc. Am. B., 2007, 24, 1512.

15. Kaczmarek M., Buchnev O., Nandhakumar I., Appl. Phys. Lett. 2008, 92, 103307.

16. Buchnev O., et al., Journal of the SID, 2005, 13, 749

17. Kundu S., et al., Jap. J. Appl. Phys., Part 1, 2008, 47, 4751.

18. Cook G., et al., Optics Express, 2008, 16, 4015.

19. Grabar A., et al., in Photorefractive Materials and Their Applications. Springer Science+Business Media LCC, New York, USA, 2007, vol.2, p. 327-362.

20. Dittmar G., Schaefer H. Zeitschrift fuer Naturforschung., 1974, 29B, 312.

21. Vysochanskii Yu.M, et al., Phase transitions in phosphorous chalcogenide ferroelectrics. Vilnius University Publishing House, 2006, 453 p.

22. Moria K., et al., J. Phys. Soc. Jpn., 1998, 67, 3505.

23. Cho Y.W., Choi S.K., Vysochanskii Y.M., J. Mater. Res. 2001, 16, 3317.

24. Frey M.H., Payne D.A., Phys.Rev.B, 1996, 54, 3158.

25. Zhao Z., et al., Phys. Rev. B, 2004, 70, 024107.

26. Li F., et al., Phys. Rev. Lett. 2007, 99, 219901.

27. Palffy-Muhoray P., Dumnur D.A., Price A., Chem.Phys.Lett., 1982, 93, 572.

28. Reznikov Yu.A., Reshetyak V.Yu., Yaroshchuk S.V. Sov.Phys. JETP 1992, 74, 816.

29. Denolf K., Cordoyiannis G., Glorieux Ch., Thoen J., Phys. Rev. E, 2007, 76, 051702.

30. Blinov L.M., Chigrinov V.G., Electrooptic Effects in Liquid Crystal Materials. Springer, 1994, p. 75

31. Madhusudana N.V., Pratibha R., Mol. Cryst. Liq. Cryst., 1982, 89, 249.

32. Reshetnyak V.Yu., Mol. Cryst. Liq. Cryst., 2004, 421, 219.

33. Reshetnyak V.Yu., Shelestiuk S.M., Sluckin T.J., Mol. Cryst. Liq.Cryst., 2006, 454, 201.

34. De Gennes P.G., Prost J., The Physics of Liquid Crystals, Oxford University Press, New York, 1994, p.148, pp 66-70.

35. Blinov L.M., Kats E.I., Sonin A.A., Sov. Phys. Usp., 1987, 30, 604 (in Russian).

36. Cordoyiannis G., et al., Phys. Rev E., 2009, 79, 011702.

37. Atkuri H., Zhang K., West J., Mol. Cryst. Liq. Cryst., 2009, 508, 183. 


\title{
Наноколоїди $\mathrm{Sn}_{2} \mathrm{P}_{2} \mathrm{~S}_{6}$ в рідкому кристалі пентил-ціанобіфенил
}

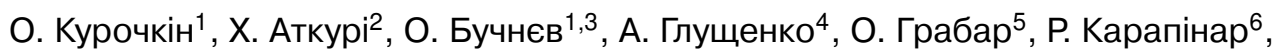 \\ В. Решетнякㄱ, Д. Вест ${ }^{2}$, Ю. Рєзніков
}

1 Інститут фізики, Національна Академія наук України, просп. Науки 46, Київ, 03028, Україна

2 Інститут Рідких Кристалів, Державний Університет Кенту, Кент, Огайо, 44242, США

3 Університет Саутхемптона, Хемпшир, Саутхемптон, SO17 1BJ, Велика Британія

4 Університет Колорадо в Колорадо Спрінгс, Департамент фізики, Колорадо Спрінгс, СО 80918, США

5 Інститут фізики та хімії твердого стану, Ужгородський державний Університет, Підгірна 46, Ужгород, 294000, Україна

6 Факультет науки та мистецтв, Департамент фізики, Юзунсу Йіл Університет, Ван, 65080, Туреччина

7 Київський Національний Університет ім. Тараса Шевченка, Фізичний факультет, вул. Володимирська 64, Київ, 01601, Україна

В роботі експериментально показано, що сегнетоелектричні наночастинки, як і інші молекулярні домішки, зміщують температуру просвітлення, $T_{\mathrm{c}}$, при цьому збільшуючи або зменшуючи область існування двофазного стану, та змінюючи середній параметр порядку однокомпонентних нематичних рідких кристалів (РК). В деяких сегнетоелектричних колоїдах спостерігалося підвищення $T_{\mathrm{c}}$ на величину до $11^{\circ} \mathrm{C}$, в інших - невеликі зниження на величину до $3{ }^{\circ} \mathrm{C}$, а також відповідні зміни параметра порядку. У всіх випадках температурні криві параметру порядку колоїду збігаються 3 універсальними кривими для РК з молекулярними домішками.

Ключові слова: рідкі кристали, сегнетоелектричні наночастинки 
